\title{
Critical Barriers to Implementing Risk Assessment and Management Practices (RAMP) in the Iranian Construction Sector
}

\author{
*Nicholas Chileshe1, M. Reza Hosseini² and Jacqueline Jepson'
}

Published online: 21 December 2016

To cite this article: Nicholas Chileshe, M. Reza Hosseini and Jacqueline Jepson. (2016). Critical barriers to implementing risk assessment and management practices (RAMP) in the Iranian construction sector. Journal of Construction in Developing Countries, 21 (2): 81-112. https://dx.doi.org/10.21315/jcdc2016.21.2.5.

To link to this article: https://dx.doi.org/10.21315/jcdc2016.21.2.5

\begin{abstract}
Late completions, frequent work stoppages and cost overruns are common issues in developing countries. Effective risk management (RM) can be utilised to address these common construction issues; however, the uptake of risk management within the Iranian construction industry, as in many developing nations, is limited. This study explored why RM is not used through a questionnaire survey of 90 professionals in the Iranian construction industry. The findings show that professionals in the industry perceive the three greatest barriers to be (1) a lack of experience among practitioners, (2) the lack of available risk management consultants and (3) a lack of knowledge and necessary skills. In contrast, the professionals believed that the least common barriers were tight scheduling of projects and costs associated with risk management implementation. No significant differences were found between the perceptions of the three sub-groups-contractors, consultants and clients (private and public)-regarding the barriers to risk management. The study contributes to the field by providing insights into what causes the low level of implementation of risk assessment and management practices (RAMP) in Iran. It is anticipated that this type of study will result in raising the level of awareness about practices designed to improve risk management in developing countries. The study advocates a number of solutions for addressing the identified barriers. These solutions can be implemented or used as guidelines by construction companies and policy makers in other developing countries confronting similar problems.
\end{abstract}

Keywords: Risk assessment, Risk management, Barriers, Developing countries, Construction industry, Iran

\section{INTRODUCTION}

Construction projects are inherently risky (Zhao, Hwang and Low, 2013). That is, construction projects operate in an increasingly dynamic and pluralistic society. This is compounded by complex relationships with owners, designers, contractors, subcontractors, suppliers, government authorities, the public and stakeholders (Hwang, Zhao and Toh, 2014). The effective implementation of risk assessment and management practices (RAMP) is indispensable to the success of construction projects (Banaitienè et al., 2011) and the successful management of risks in projects facilitates the achievement of the projects' objectives (Zou et al., 2006). However, the uptake of risk management (RM) practices among construction organisations in Iran still remains very low (Ghahramanzadeh, 2013). Promoting

ISchool of Natural and Built Environments, University of South Australia, Adelaide, SA 5001, AUSTRALIA

2 School of Architecture and Built Environment, Deakin University, Geelong, Victoria, AUSTRALIA

*Corresponding author: Nicholas.chileshe@unisa.edu.au 
RAMP by conducting further research into the Iranian construction industry has been regarded as relevant and necessary by previous researchers (Zadeh, 2010; Tavakkoli-Moghaddam, Mousavi and Hashemi, 2011). Despite the existence of some studies of RM within the Iranian construction industry, the majority of these studies have focused on developing quantitative methods for identifying risks; see, for example, Mojtahedi, Mousavi and Makui (2010) and KarimiAzari et al. (2011). These studies fail to consider why the Iranian construction industry has been a poor adopter of RAMP (Chileshe and Kikwasi, 2014). There is a need to explore the barriers to RM implementation within the construction industry of Iran. This study aims to fill this knowledge gap; firstly, by identifying the barriers to RAMP implementation in a developing country and secondly, by suggesting remedial solutions to overcoming the identified barriers.

This Iranian-based study will also reinforce previous researcher's analysis of the barriers to the implementation of RAMP in developing countries and their suggested solutions for removing these barriers. The barriers to implementing risk and related management practices in developing countries generally is an overlooked area of study (Chileshe and Kikwasi, 2013, 2014; Perera et al., 2014). Consequently, there are several ways this study will contribute to the existing body of the knowledge. Firstly, it will add to the understanding of the inhibitors of construction risk in developing countries. Secondly, the findings will provide insights for policy makers in the construction industries of developing countries that will highlight the underlying reasons for the existence of barriers to RM and suggest possible measures that could be employed to overcome these barriers.

This study is unique because it investigates RAMP using Iran as an example of a developing country and because it provides a comparison for the barriers identified for developing countries by other studies.

\section{LITERATURE REVIEW}

The following section provides the context for this Iranian-focused study by providing information on the significance of the construction industry and its projects to developing countries, including Iran. This section will identify the barriers to RAMP within the broader context of developing countries and will extend the analysis using Iran as a case study. Thus, the literature review is structured according to the following three areas: (1) construction projects in developing countries, (2) barriers to ramp in developing countries and (3) barriers to RAMP in Iran.

\section{Construction Projects in Developing Countries}

In Iran, as in many developing countries, the construction industry is a major contributor to gross domestic product (GDP) and is a pillar of the national economy (Ghoddousi et al., 2014). The construction industry in Iran has been growing at an astonishing rate. This is largely due to an increase in national and international investment, and Iran's construction industry is now the largest of its type in the Middle Eastern region (Ifpinfo.com, 2014). Despite this growth, construction projects in developing countries are fraught with low productivity and frequent work stoppages (Ghoddousi et al., 2014). This low productivity has been 
exacerbated by low retention of employees (Arashpour, Shabanikia and Arashpour, 2012) and by construction practitioners who lack the prerequisite skills (Tabassi and Bakar, 2009). Furthermore, as a developing country, Iranian construction projects are prone to a wide range of uncertainties (Ebrahimnejad, Mousavi and Seyrafianpour, 2010) and market volatilities (Fereidouni, 2011). Studies such as Jahangiri, Izadkhah and Jamaledin (2011) have identified Iran's location as being among the top disaster-prone countries in the world; therefore, disaster management is considered one of the most important issues in this country. Construction projects in developing countries often have to contend with government instability, lagging political and institutional reforms and inefficient and inequitable education systems to train the large transient worker population (International Monetary Fund, 2014).

These issues further highlight the need for effective RM practices. Nevertheless, as previously research has noted, "as a developing country, Iran has not focused on RM" (Tadayon, Jaafar and Nasri, 2012). RAMP is not regarded as an essential element of delivering projects by the construction industries of developing countries (Tadayon, Jaafar and Nasri, 2012). Implementing RM in developing countries becomes more necessary, as developing countries are prone to political risks that cause great uncertainty for construction projects (Deng et al., 2014; Perera et al., 2014).

Evidence attests that developing countries show a lack of interest in implementing RM to mitigate ongoing issues in the construction industry (Silva, Wu and Ojiako, 2013). The application of RAMP in developing countries has remained in the early stages (Chileshe and Kikwasi, 2014). As early as 1997, Rao Tummala et al. (1997) suggested that the low levels of RAMP implementation was caused by barriers or difficulties faced by construction companies, such as lack of information, human/organisational resistance, lack of understanding of RAMP, lack of knowledge and cost constraints.

\section{Barriers to RAMP in Developing Countries}

For brevity, the selected studies of the main barriers to RAMP implementation, as identified in the literature and previously reported in Chileshe and Kikwasi (2014), are illustrated in Table 1. 
Table 1. Selected Studies of Barriers to RAMP Application in Developed and Developing Countries

Researchers'/Context
Rao Tummala et al. (1997):
Survey of 52 building services
engineers responsible for cost
estimation in the Building
Services Branch (BSB) in Hong
Kong

Kim and Bajaj (2000): Interviews of 13 Korean managers of general construction firms

Lyons and Skitmore (2004): General survey of 17 contractors, 11 consultants, 10 clients and six developers in Queensland (Australia) construction engineering organisations

Liu et al. (2007)2: General survey of contractors' attitudes in China

Tang et al. (2007)2: General survey of 115 stakeholders including 19 clients, 30 contractors, 21 designers, 20 superintendents, management organisations, eight planning organisations and seven others in China

\section{Findings}

Barriers to RAMP expressed in terms of "inherent problems" and "implementation problems encountered". Identified the following five inherent problems encountered during the implementation of risk management processes (RMP): difficulty in obtaining input estimates and assessments of their probabilities, time involvement, difficulty in understanding and interpreting the outcomes of RMP and managers cannot agree on the quantification of uncertainty/subjective probability. The following five were the "implementation problems encountered" in ranked order: (1) human/organisational resistance to change, (2) managers' understanding of RM process techniques, (3) lack of computing resources and assistance, (4) lack of middle management support and (5) lack of top management support.

Three reasons limiting the usage of RM techniques: a lack of familiarity with techniques, most clients and/or owners wanted to see tangible calculations and unambiguous evidence of risk and lack of expertise with techniques

Identified nine barriers inhibiting the implementation of RM: lack of time, lack of familiarity with the techniques, lack of dedicated resources, lack of expertise, lack of information, difficulties in seeing the benefits, human/organisation resistance, lack of an accepted industry model for analysis and cost effectiveness.

Investigated the key issues and challenges in RM and insurance in the Chinese construction industry: contractors' attitudes and perception, knowledge, cultural considerations, lack of experience and expertise

Eleven barriers to RM: lack of joint management mechanisms by parties, shortage of knowledge of/techniques for RM, different recognition of risk control strategies, ineffective implementation of risk control strategies, lack of formal risk control strategies, ineffective monitoring, lack of formal RM systems, no incentive for better RM, lack of risk consciousness, inappropriate risk allocation, lack of historical data for risk trend analysis, inappropriate risk allocation and insufficient ongoing project information 
Table 1. (Continued)

Wang, Fang and Pham (2009)3: Interviewees from government agencies and organisations and Australian firms in China

Harner (2010)4: Critical review of legal-related studies considering the impact of boardroom dynamics and United States corporate culture on RM practices.

Kikwasi (2011): Interviews of 55 consultants, architects and quantity surveyors in Tanzania

Chileshe and Yirenkyi-Fianko (2012)*: General survey of 34 contractors, 46 consultants and 23 clients (public and private) in construction projects in Ghana

Carter and Chinyio (2012): A questionnaire survey of 113 construction professionals (project managers, clients, quantity surveyors and contract experts) in the United Kingdom

Paape and Speklè (2012): Surveyed respondents (chief financial officers, controllers and risk managers) from 825 organisations with annual revenues of more than EUR 10 million and more than 30 employees in the Netherlands
Identified the following three major risks: (1) IP protection, (2) complex networks of policies and (3) decrees and regulations and identified fragmentation or conflicts among them imposed by the state, industry and local government.

Examined the following two possible barriers to RM: (1) individual biases and (2) cultural norms. Three cognitive biases (confirmation bias, overconfidence/optimism, and framing) that may impede risk assessment were analysed, and the study explored whether "corporate culture" and "the environment at entrepreneurial or risk-aggressive firms" posed a barrier to effective risk-management practices.

Identified four challenges: inadequate risk management knowledge, risk management not a priority in clients' requirements, lack of a holistic approach to risk management and reluctance among consultants to spearhead the risk management process

Identified seven main barriers to risk assessment and management practices: awareness, lack of experience, lack of coordination between parties involved, lack of information, availability of specialist RM consultants, time constraints and lack of knowledge and expertise

Identified the following barriers: making a late start, using inexperienced personnel, attitude towards risk not robust enough, incompetency of risk managers and not fully pro-active

Identified the following five broad group of factors as antecedents to ERM implementation: (1) regulatory influences, (2) internal influences, (3) ownership, (4) auditor influence and (5) firm and industry-related characteristics 
Table 1. (Continued)

Hwang, Zhao and Toh (2013): A
questionnaire survey of 15
consultants and 19 contractors in
Singapore based on data
collected from 668 projects

Chileshe and Kikwasi (2014): A questionnaire survey of 24 contractors, 15 clients, and 27 consultants in Tanzania
Identified 10 probable barriers to RM implementation in small project: competition among small and medium contractors (SMC), complexity of analytical tools, lack of potential benefits, lack of budget, lack of government legislation, lack of knowledge, lack of manpower, lack of time; low profit margin and not economical

Based on overall mean sample scores, identified the following ten CSFs for the implementation of RAMP in ranked order: (1) awareness of RM, (2) teamwork and cooperation, (3) management style, (4) effective use of methods and tools, (5) goals and strategic objectives of the organisation, (6) availability of a specialist RM consultant, (7) consideration of the external and internal environment, (8) cooperative culture, (9) customer requirement and (10) positive human interactions

Source: Chileshe and Kikwasi (2014)

Notes: 'The studies are arranged in chronological order; *This current study is based on the survey instrument as utilised in Chileshe and Kikwasi (2014); ${ }^{2}$ Selected studies within the Chinese context; ${ }^{3} \mathrm{General}$ risk identification study; ${ }^{4}$ Non-construction-related study

In their Malaysian study, Goh and Abdul-Rahman (2013) identified the lack of knowledge of RM and the costs associated with implementing RM as major barriers. Choudhry and labal (2013) concluded that the most significant barriers were the lack of a formal RM system and the lack of a mechanism for joint RM by stakeholders in Pakistan. This finding was echoed in the study conducted by Silva, Wu and Ojiako (2013) in Sri-Lanka, in which the limited awareness of best practices, the lack of qualified expertise and the time required for and the and costs of RAMP were detected as barriers. The lack of knowledge regarding RAMP in Sri-Lanka was later acknowledged by Perera et al. (2014) as a barrier to the effective implementation of RAMP. By the same token, Liu, Low and He (2011) found that Chinese construction companies lacked the expertise and knowledge required for the practical implementation of RAMP, as RAMP has had only a short period of exposure in China.

In a study of Ghana, Chileshe and Yirenkyi-Fianko (2012) identified the major barriers to RAMP implementation as the lack of information, awareness and experience; the ineffective coordination between the parties involved; the unavailability of specialist RM consultants and the tight scheduling of construction projects. Using the same survey instrument employed by Chileshe and YirenkyiFianko (2012) in Ghana, an empirical survey study was conducted by Chileshe and Kikwasi (2014) in the context of the Tanzanian construction industry. The findings of that study identified the following seven barriers to RAMP implementation, in ranked order:

1. awareness of RM processes,

2. lack of experience,

3. lack of information, 
4. lack of coordination between the parties involved,

5. availability of specialist RM consultants,

6. implementation costs and

7. time constraints.

It should be noted that while the identified studies of Chileshe and YirenkyiFianko (2012) used the terminology of RAMP, the RAMP and RM concepts are the same. The two terms are used interchangeably and are the same when applied in the Iranian study.

Acknowledging the impact of a lack of knowledge regarding the implementation of RAMP, Rao Tummala et al. (1997) suggested that the resources necessary for implementing RAMP could not be justified, as the uncertainties and the potential benefits of implementing RAMP in construction projects were unknown. A review of the literature establishes that research on RM has been extensive. However, few studies have focused on detecting the barriers to RAMP implementation. Apart from a limited selection of studies (i.e., Chileshe and Kikwasi, 2013; 2014), there is no research focusing on identifying the barriers to the implementation of RAMP within the construction context of developing countries. Hence, given the salience of RAMP for construction projects in developing countries, the primary objective of the present study (ascertaining the barriers to RAMP implementation and devising corresponding solutions) is further reinforced.

\section{Barriers to RAMP in Iran}

Given the scarcity of studies of barriers to RM in Iranian construction projects, some selected studies with associations to RM were also included in the review of the literature. These included studies mainly in the areas of disaster management, business process re-engineering and knowledge management (KM). Table 2 presents a summary of the selected RM and comparative studies.

Table 2. Summary of Selected RM and Comparative Studies in Iran

\begin{tabular}{|c|c|c|}
\hline Researchers $^{1}$ & $\begin{array}{l}\text { Aim, Methodology and } \\
\text { Context/Scope }\end{array}$ & Findings \\
\hline $\begin{array}{l}\text { Nateghi-A. } \\
(2000)\end{array}$ & $\begin{array}{l}\text { Aimed to present the existing } \\
\text { organisational chart of } \\
\text { earthquake disaster } \\
\text { management in Iran. The } \\
\text { methodology was a general } \\
\text { review and the scope was } \\
\text { disaster management }\end{array}$ & $\begin{array}{l}\text { Identified weaknesses in the system } \\
\text { and proposed a modified } \\
\text { organisation for better management } \\
\text { and handling of earthquake crises in } \\
\text { Iran }\end{array}$ \\
\hline
\end{tabular}

(Continued on next page) 
Table 2. (Continued)

$\begin{array}{ll}\text { Jafari et al. } & \text { This paper aims to discuss the } \\ \text { (2007) } & \text { essential issues of KM adoption } \\ & \text { to establish a KM programme in } \\ & \text { the Iran Aerospace Industries } \\ & \text { Organization (AIO). A case } \\ & \text { study methodology was applied } \\ & \text { in the area of KM }\end{array}$

Identified the following eight factors as essential for $\mathrm{KM}$ : (1) team work and KM features, (2) leadership and commitment of Chief Executive Officer (CEO), (3) appropriate organisational infrastructure, (4) pilot, benchmarking and KM systems, (5) job enrichment and security, (6) culture, change management and strategy, (7) collaborative and flexible organisation and (8) training and learning.

Fallahi (2008) Analyses the extent to which such opportunities were capitalised upon and proposes strategies and recommendations for future risk preparedness planning in Bam, Iran. A case study methodology was applied in the area of disaster and RM

Tarokh, Sharifi and Nazemi (2008)

This paper aims to study the success and failure of business process re-engineering (BPR) projects executed throughout Iran. The methodology included a statistical analysis of the mean values of efficiency and project effectiveness indexes, whereas the scope was in business process re-engineering and business failure

Parsizadeh and This paper seeks to provide a Ghafory-Ashtiany (2010) brief summary of a comprehensive earthquake education programme for increasing public awareness and preparedness for earthquakes using all types of media, particularly in schools and amongst children. It employed a literature review, and the scope was in RM and disaster management

Ebrahimnejad, Mousavi and The main aim was to understand risks in buildSeyrafianpour operate-transfer (BOT) projects

An earthquake provided an opportunity for the further development and growth of the city's unique and internationally known date production through more publicity, renovation of the old irrigation systems, and the expansion of its related industries

BPR projects executed in Iran have failed to reach a predefined acceptable level of success

Established that there is still a long way to go to achieve a fully prepared and seismically safe community and that to enhance public safety, stronger cooperation by and participation of the entire of society are necessary 
Table 2. (Continued)

\begin{tabular}{|c|c|c|}
\hline $\begin{array}{l}\text { Jafari et al. } \\
(2011)\end{array}$ & $\begin{array}{l}\text { This study sought to develop a } \\
\text { model for RM of knowledge loss } \\
\text { in a project-based organisation } \\
\text { in Iran. A case study } \\
\text { methodology was applied in } \\
\text { the area of KM and RM }\end{array}$ & $\begin{array}{l}\text { The proposed model had the ability } \\
\text { to reduce the job positions facing } \\
\text { knowledge loss by } 88 \%\end{array}$ \\
\hline $\begin{array}{l}\text { Jahangiri, } \\
\text { Izadkhah and } \\
\text { Jamaledin (2011) }\end{array}$ & $\begin{array}{l}\text { The study's aim was to conduct } \\
\text { a comparative study of } \\
\text { community-based disaster } \\
\text { management (CBDM) in various } \\
\text { selected countries to design a } \\
\text { model for Iran. Used a } \\
\text { descriptive comparative study } \\
\text { methodology in the area of } \\
\text { disaster management (DM) }\end{array}$ & $\begin{array}{l}\text { Participation of the community in } \\
\text { various disaster management } \\
\text { lifecycles was identified as necessary } \\
\text { for effective (successful) disaster } \\
\text { management }\end{array}$ \\
\hline $\begin{array}{l}\text { Tadayon, Jaafar } \\
\text { and Nasri (2012)* }\end{array}$ & $\begin{array}{l}\text { The study was focused on } \\
\text { research identification rather } \\
\text { than other processes of RM. The } \\
\text { methodology employed was a } \\
\text { questionnaire survey, and the } \\
\text { scope was RM }\end{array}$ & $\begin{array}{l}\text { Established that time constraints and } \\
\text { project managers with sufficient } \\
\text { experience are critical when } \\
\text { identifying the level of risk for large } \\
\text { and/or complex projects }\end{array}$ \\
\hline $\begin{array}{l}\text { Alavifar and } \\
\text { Motamedi } \\
(2014)^{* 2}\end{array}$ & $\begin{array}{l}\text { The study aimed to identify } \\
\text { delayed risks for construction } \\
\text { projects from the owners', } \\
\text { contractors' and consultants' } \\
\text { perspective; it also evaluated } \\
\text { and classified risks. Employed a } \\
\text { methodology of data collection } \\
\text { through a questionnaire survey. } \\
\text { The scope was in RM }\end{array}$ & $\begin{array}{l}\text { Classified the levels of problems } \\
\text { related to the time delay risks of } \\
\text { construction projects into the } \\
\text { following three categories: (1) } \\
\text { Managerial, (2) Systematic and (3) } \\
\text { Strategic. Different ranking of } \\
\text { frequency, severity and importance } \\
\text { of the causes of delay by the three } \\
\text { groupings (owners, contractors and } \\
\text { consultants) }\end{array}$ \\
\hline $\begin{array}{l}\text { Bowers and } \\
\text { Khorakian }(2014)^{*}\end{array}$ & $\begin{array}{l}\text { The study sought to establish the } \\
\text { types of projects to which risk } \\
\text { management should be } \\
\text { applied and at what points they } \\
\text { should be applied in an } \\
\text { innovation project. It employed } \\
\text { a dual methodology of a } \\
\text { research framework and a case } \\
\text { study. The scope was in project } \\
\text { RM and innovation process }\end{array}$ & $\begin{array}{l}\text { Established that RM needs to be } \\
\text { applied in a differential manner: } \\
\text { simple, unobtrusive techniques early } \\
\text { in the innovation life cycle with more } \\
\text { substantial, quantitative methods } \\
\text { being considered for the later stages }\end{array}$ \\
\hline
\end{tabular}

Notes: 'The studies are arranged in chronological order; *Specific RM studies; ${ }^{2}$ Study based on a literature review of RM drawn from similar Middle Eastern countries such as the United Arab Emirates (UAE), Saudi Arabia, Turkey, Lebanon, Kuwait, and Jordan and from other developing countries such as Malaysia, Nigeria and Libya; For the purpose of our current study, the terminology RM is used interchangeably with RAMP 


\section{RESEARCH METHODS}

This research is based on data collected via a survey questionnaire. A survey was chosen because exploring variables that are similar across construction projects in a certain context (e.g., a country) justifies deploying a quantitative approach such as a survey questionnaire (Amaratunga et al., 2002).

\section{Design of the Survey Instrument}

The questionnaire used for this study was adapted from a validated instrument, i.e., the questionnaire employed by Chileshe and Kikwasi (2014) in their study of the Tanzanian context. According to Carless and De Paola (2000), adapting and customising available instruments for the specific environment targeted by a research study is acceptable. Thus, to customise the data collection tool for Iran, (in the absence of standard or validated RAMP barriers questionnaire) the approach suggested by Sharifirad's (2011) protocol was followed. Sharifirad's (2011) procedure required the translation and review of the questionnaire. The Chileshe and Kikwasi (2014) questionnaire required translation (from English into Persian and vice versa) and a review of the items contained therein. This involved forward translation, assessment, backward translation and assessment.

As part of the identified four-step procedure, the basic instrument was presented to four Iranian project managers who each have more than 12 years of experience with construction projects. The questionnaire was approved by the project managers, who also suggested that the technical terms (e.g., RM terminology) be fully clarified. Consequently, specific definitions were added to the questionnaire to make the objectives clear for potential respondents. The rationale for submitting the questionnaire to the Iranian project managers is further supported by Forza (2002), who states that "industry experts" should be involved in the pre-testing of a questionnaire. The final questionnaire retained the same number of items (seven) as the original Chileshe and Kikwasi (2014) instrument; however, the content was slightly different because a number of changes were made. The first barrier (BR1) and third barrier (BR3) in the Chileshe and Kikwasi (2014) questionnaire were "Awareness of RM instrument" and "Lack of information"; these were deleted from the Iranian RM sub-instrument and replaced with the following barrier: "Lack of knowledge and necessary skills".

The third barrier relating to "information" was also replaced with a barrier called "Lack of support from clients and project stakeholders". The remainder of the changes were related to the terminology used in the wording of the questions. The final questionnaire consisted of the following two sections:

1. Section 1 asks about the demographic attributes of respondents and

2. Section 2 is concerned with the views of the respondents regarding the levels of importance of the barriers to RM. The respondents were asked to rate the importance of the barriers to RM implementation using a 5-point Likert scale, ranging from "1" as the least important (or strongly disagree) to "5" as the most important (or strongly agree). 


\section{Survey Administration}

According to Roudsari and Ghodsi (2005) and Ghoddousi et al. (2014), as the capital and most populated city of the country, Tehran has a large pool of construction company headquarters. Consequently, Tehran brings together the country's construction practitioners. Thus, construction practitioners in Tehran were targeted as the respondents to the survey.

Lists of certified companies were obtained from the data bank of licensed construction companies consistent with the method utilised by Ghoddousi et al. (2015) for targeting construction companies in Iran. These lists were merged and sorted alphabetically. Subsequently, a random selection of the outcomes was performed using a non-replacement random selection technique consistent with that employed by Ghoddousi and Hosseini (2012).

An average response rate of $20 \%$ was observed in previous studies in Iran (e.g., Ghoddousi et al., 2015). Thus, to obtain a minimum of 100 completed questionnaires for the sake of conducting complicated statistical analyses such as structural equation modelling (SEM), a total of 494 invitations were sent by post to the selected companies. The respondents were invited to distribute the questionnaire among their employees involved in construction projects. Follow-up calls were conducted and resulted in the receipt of 90 completed questionnaires. The process of preparing the list, conducting the data collection and entering the data took seven months and was completed at the end of May 2013.

\section{Instrument (Measurement) Validity and Reliability}

As recommended by Forza (2002), the internal consistency of the survey was tested using reliability analysis. The Cronbach's alpha was found to be 0.714 for the RM barriers sub-instrument, which was greater than 0.7, thus indicating an acceptable level of reliability.

\section{Analysis of Results}

A number of data analysis techniques were employed in this study and were consistent with those used by previous studies investigating the barriers to RM (Liu, Low and He, 2011; Chileshe and Kikwasi, 2013); these are described next.

\section{Multivariate Analysis of Variance (MANOVA)}

To test whether different groups of stakeholders differed in their perception of the barriers to RM, a MANOVA test was undertaken. This approached was used to consider the different attributes of respondents with respect to their perceptions of the barriers to RAMP. In developing countries such as Iran, clients and companies form the basic units of the construction industry, as described by Moavenzadeh (1978). Similarly, according to the main source of information for licensing construction companies in Iran (see http://www.sajat.in/), licenses are issued in two main categories. These categories are represented by contractors and consultants, who, together with clients, form the necessary elements for delivering a construction project (Moavenzadeh, 1978). 
The respondents were divided into three groups according to their role in the construction industry (Group 1 = Clients, Group 2 = Consultants and Group $3=$ Contractors). This approach enabled the researchers to compare the viewpoints of the primary entities active within the Iranian construction industry. Including a range of respondents is important because a respondent in one role may express a different viewpoint regarding aspects associated with RM than a respondent in a different role (Perera et al., 2014). The inclusion of the three groups (contractors, consultants and clients) is highly desirable, as previous studies in the area of RM relied mainly on one group of project participants. According to Tang et al. (2007), project risks cannot be controlled by one party. By the same token, this exploration of the perception of barriers to RAMP had to rely on a wide range of project participants.

\section{Spearman's Rank Correlation Coefficient}

Equation 1, i.e., Spearman's rank correlation coefficient $\left(r_{s}\right)$, which was used to analyse the bid/no bid factors by Cheung et al. (2012), was deployed in the present study.

$$
r_{s}=1 \frac{6 \sum d^{2}}{N\left(N^{2}-1\right)}
$$

where:

$d=$ the difference in the rankings of the two groups for the same barrier to RM and $N=$ the total number of responses concerning that barrier to RM (7, in this case).

\section{Partial Least Square Structural Equation Modelling (PLS-SEM)}

According to Hair et al. (2014), for research studies in which there is no established theory to explain the associations between the concepts, the application of PLSSEM becomes relevant. Unlike Covariance-based Structural Equation Modelling (CB-SEM), PLS-SEM is robust to small sample sizes and presents accurate results when normality requirements for the data are not met (Ringle, Sarstedt and Straub, 2012). PLS-SEM is very capable of interrogation of the data to explore and reveal associations among a number of constructs (Hair et al., 2012). Given the relatively small sample size and the novelty of the concepts in the present study, PLS-SEM was considered a rigorous statistical method for analysing the data. SmartPLS v.3.2.1, as recommended by Hair et al. (2014), was used to perform the SEM-PLS analysis.

\section{Characteristics of the Sample}

The characteristics of the respondents and their organisations are summarised in Tables 3 and 4, respectively. 


\section{Individual characteristics}

An examination of Table 3 shows that the majority (33.0\%) of the respondents were supervisors, followed by design engineers (21.6\%) and project managers or site managers (14.8\%). Thus, it was concluded that the respondents had gained firsthand experience in delivering construction projects and were knowledgeable about the management strategies of their companies.

\section{Length of service in the construction industry}

The results revealed that the respondents' length of experience (employment) in the Iranian construction industry was evenly distributed across the spectrum: Less than five years, 5-10 years, 11-15 years and more than 15 years (Table 3 ). The respondents represented all the levels of experience within the Iranian construction industry. Given the diversity in length of service in the construction industry (see Table 3) and the variability of roles represented, this sample provides a wide range of the common views prevalent within the Iranian construction industry.

The majority of the respondents (68.5\%) had more than five years of experience in the Iranian construction industry. This is highly significant given that frequently used risk assessment techniques are highly dependent on intuition, judgement and experience (Lyons and Skitmore, 2004). As such, it could be inferred that the level of experience among the Iranian practitioners would contribute towards mitigating some of the barriers associated with implementing RM.

Table 3. Profile of the Study Sample (Professional Background and Experience)

\begin{tabular}{lccc}
\hline Characteristics & $\begin{array}{c}\text { Number of } \\
\text { Respondents }\end{array}$ & $\%$ & Cumulative \\
\hline Professional and trades background & 29 & 32.94 & 32.94 \\
Supervisor & 19 & 21.60 & 54.54 \\
Design engineer & 13 & 14.77 & 69.31 \\
Project manager & 12 & 13.64 & 82.95 \\
Site manager & 15 & 17.05 & 100.0 \\
"Other & & & \\
Experience in the construction industry & 28 & 31.1 & 31.5 \\
Less than five years & 27 & 30.0 & 61.8 \\
5-10 years & 20 & 22.2 & 84.3 \\
11-15 years & 14 & 15.6 & 100.0 \\
More than 15 years & & & \\
\hline
\end{tabular}

Notes: "The profile of the professional and trades background is based on sample size of 88 due to some missing data 


\section{Organisational characteristics}

The profile of the respondents in terms of their roles is illustrated in Table 4.

Table 4. Profile of the Study Sample (Role in Projects)

\begin{tabular}{lccc}
\hline Role in Projects & Number of Respondents & $\%$ & Cumulative\% \\
\hline Contractor $^{1}$ & 32 & 35.6 & 35.6 \\
Consultant & 31 & 34.4 & 70.0 \\
Client (private and public) $^{2}$ & 27 & 30.0 & 100.0 \\
\hline
\end{tabular}

Notes: 'The contractor group includes one specialist sub-contractor and 1 operator; According to the formal classification of contractors currently in place in Iran, construction companies active in government projects are classified into five categories. Those in class 1 are allowed to undertake projects with the biggest budgets (Ghoddousi and Hosseini, 2012); ${ }^{2}$ The construction industry of Iran is divided into two main sections: The first is government infrastructure projects and the second is the housing industry (Ifpinfo.com 2014)

As seen in Table 4, there is a fairly equal distribution of the three key players in projects. Such an equal distribution has also been observed in other studies conducted in the Iranian construction industry as well (Pournader, Tabassi and Baloh, 2015).

\section{RESULTS AND DISCUSSION}

\section{Identified Barriers to Implementing RAMP}

The overall ratings of the barriers to implementing RAMP according to the overall sample and the groups are shown in Table 5.

The ranking differentiation between barriers with the same mean was achieved using the coefficient of variation (CV). The use of the $\mathrm{CV}$, obtained by dividing the mean score by the standard deviation, has been adopted by previous researchers (Chileshe and Kikwasi, 2014; Ghoddousi et al., 2014). Hence, the $\mathrm{CV}$ has been used as an acceptable basis for meaningful evaluations of respondents' level of consensus on different items in construction research (Ghoddousi et al., 2014). It shows the extent of variability in relation to the mean of the population. 
Implementing RAMP in the Iranian Construction Sector

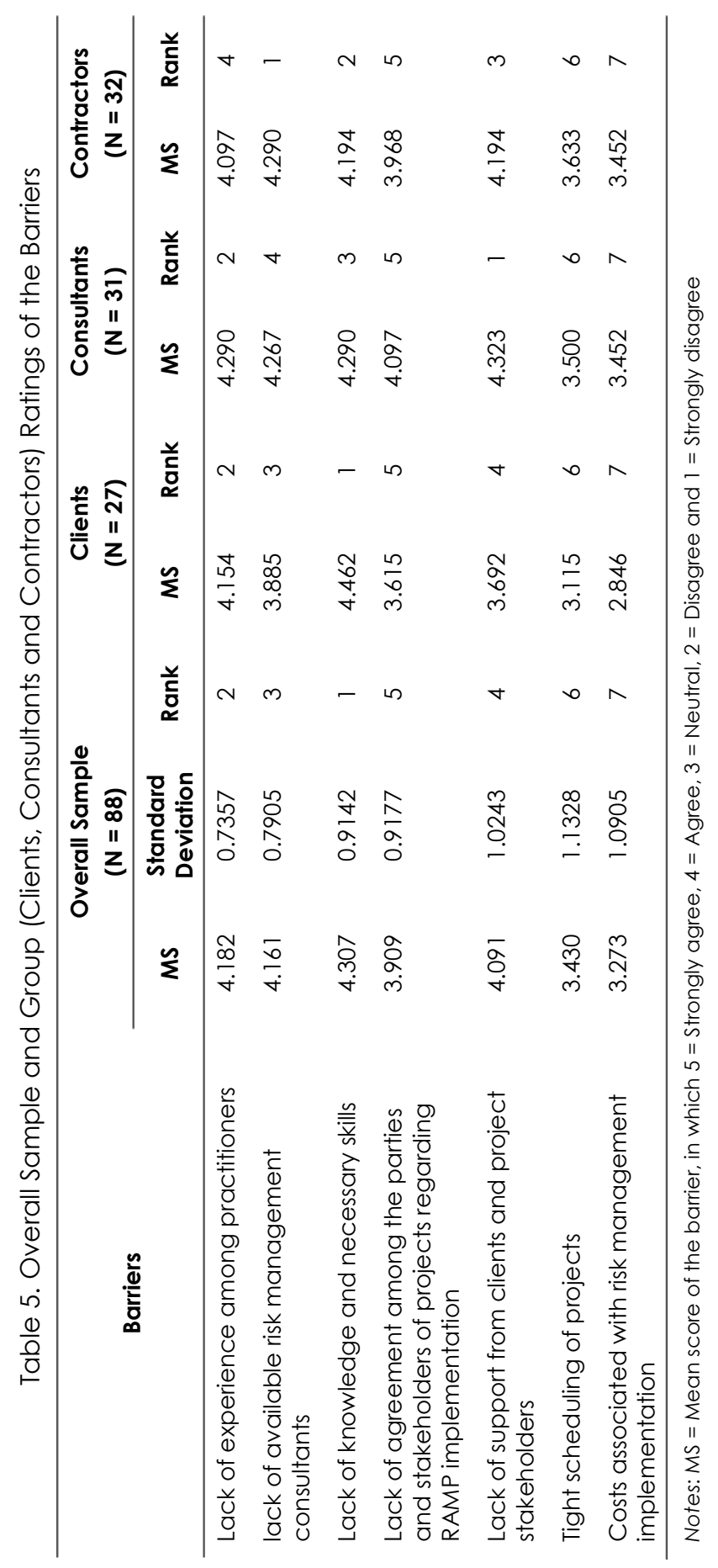

PENERBIT UNIVERSITI SAINS MALAYSIA/95 


\section{Multivariate Analysis of Variance (MANOVA)}

To ensure the accurate interpretation of the responses, an analysis of the respondents' profile was compared to their perception of barriers. Utilising a multivariate analysis of variance (MANOVA), as proposed by Ghoddousi et al. (2014), is widely accepted within the literature. That is, deploying several univariate tests for each item increases the potential for Type I error, according to Cronk (2012). By employing a MANOVA, the causes of error are contained, which allows statistical analyses to take place at the same time (Abbott, 2011). According to Cronk (2012), the most common multivariate test is Wilks' Lambda. Thus, a one-way MANOVA was performed to examine the potential discrepancies among the respondents' perceptions regarding seven items identified as barriers to RAMP implementation, as illustrated in Table 6.

Table 6. Wilks' Lambda Result (MANOVA Tests)

\begin{tabular}{|c|c|c|c|c|c|}
\hline Effects & Value & $\boldsymbol{F}$ & $\begin{array}{c}\text { Hypothesis } \\
\text { df }\end{array}$ & Error $d f$ & Sig. \\
\hline Role in projects* & .799 & $1.292 \mathrm{~b}$ & 14.000 & 152.000 & .218 \\
\hline Professional and trades** background & .584 & 1.520 & 28.000 & 264.627 & .054 \\
\hline Experience in the construction ${ }^{* *}$ industry & .806 & .791 & 21.000 & 213.038 & .729 \\
\hline
\end{tabular}

Notes: "Table 4; "* Table 3

The results of the one-way MANOVA illustrated in Table 6 showed no significant effect of the different categories associated with the respondents' profile on the respondents' perceptions of the barriers to RM implementation. That is, the results indicated that there is no difference between the perceived barriers to RM among the Iranian construction practitioners in terms of their role in projects $($ Lambda $(14,152)=.799, p=.218>0.05)$. The same results were observed among the respondents who had different professional backgrounds (Lambda $(28,264.62)$ $=.584, p=.054>.05)$ and different levels of experience $($ Lambda $(21,213.038)=$ $.806, p=.729>0.05)$. This was reflective of the consensus among the Iranian construction practitioners regarding the barriers to RAMP implementation in the construction industry. This is a logical result, as the major barriers identified in the study were associated with the lack of knowledge and experience and the unavailability of skilled personnel for RAMP. This also reinforces the assertions by Ghoddousi et al. (2015), which suggest that there is consensus among all the practitioners regarding the unavailability of skilled personnel at different levels and the lack of training for practitioners in the industry. In essence, the issues that result from this lack of knowledge are a major source of the problems that are rampant in the construction industries of developing countries, as argued by Ofori and Toor (2012). This justifies why multivariance analysis of variance (MANOVA) did not show any significant discrepancy among different respondents.

\section{Overall Ranking of the Barriers to RAMP}

This subsection examines the contractors', clients' and consultants' perception of the barriers to implementing RM. Table 5 summarises the results of the analysis of 
the barriers according to the overall sample and the respondent groups (contractors, clients and consultants).

The barriers were not grouped into specific categories because factor analysis was not undertaken. However, the ranking and severity of these barriers indicated the need to group them into the following three areas: (1) lack of formal RM systems, (2) lack of agreement and support among parties and (3) project constraints related to time and cost that inhibit the use of resources for RAMP. To build on the findings and to utilise the literature effectively, the barriers to RAMP will be discussed according to the three above-mentioned groups rather than individually.

\section{Lack of Formal RM Systems}

As illustrated in Table 5, based on the overall sample size, the highest ranked barriers impeding the implementation of RM within the Iranian construction context are:

1. lack of knowledge and necessary skills (mean $=4.307$ ),

2. lack of available RM consultants (mean $=4.161$ ), and

3. level of experience among practitioners (mean $=4.182$ ) within the Iranian construction industry.

An examination of Table 5 shows that the clients ranked "Lack of knowledge and necessary skills" first, whereas the contractors ranked "Lack of available RM consultants" first; interestingly, the consultants ranked "Lack of support from clients and project stakeholders" first. This finding demonstrates that both the clients and consultants attribute the major barriers to RM to each other's inaction (i.e., availability and cooperation). This corroborates the observations made by Kululanga (2012) regarding the serious impacts of adversarial relationships, the prevalence of the blame game prevalent and the lack of joint efforts in the construction industry in developing countries.

The findings are also consistent with the literature on barriers to RM (e.g., Wang, Dulaimi and Aguria, 2004; Choudhry and lqbal, 2013). Choudhry and lqbal (2013: 47) collectively labelled the grouping of these three barriers as a "Lack of formal RM systems". It should, however, be noted that some previous studies provide contradicting views regarding the need for formalised RM processes. For example, Khan and Burnes (2007) argued that effective RM does not need to be a highly formalised and structured process but that it should instead be based on good common sense. This study opted to include the "Lack of formal RM systems" as a barrier due to the complex nature of estimating the probability and impact of risk, as well as to the support by the majority of studies for formalised RM systems (e.g., Tah and Carr, 2001). Similarly, within the contexts of international projects and developing countries such as China, Wang, Dulaimi and Aguria (2004: 238) emphasised the "formal" nature concept by defining RM as "a formal and orderly process of systematically identifying, analysing, and responding to risks throughout the life-cycle of a project to obtain the optimum degree of risk elimination, mitigation and/or control". 
This study has collectively categorised these barriers as a "Lack of formal RM systems" based on the assumptions of the Pakistan study by Choudhry and Iabal (2013; 47). The higher ranking achieved by these barriers is hardly surprising as they are all associated with the lack of either "experience" or "knowledge". As observed by Kazaz and Ulubeyli (2007) and Ofori and Toor (2012), the two most prominent features of the economics of developing countries are low levels of education, training, and skill among the work force and insufficient infrastructure. Iran is a developing country facing similar issues to those identified by (Tabassi and Bakar, 2009) and acknowledged by Ghoddousi et al. (2015).

These findings also reiterate the observations made by Tadayon, Jaafar and Nasri (2012) and Bowers and Khorakian (2014) indicating that RM is rarely implemented in the Iranian construction industry due to the absence of knowledge and proficiency. In accordance with this observation, Wang and Yuan (2011) and Chileshe and Kikwasi (2014), contended that an awareness of RM practices and methods of implementation is a critical success factor for implementing RM. The implication of this finding is that, as observed by Choudhry and labal (2013), without a formal RM system, implementing RM in construction companies becomes dependent on the expertise and knowledge of employees or external experts. As shown in Table 5 by the higher ranking of these barriers, the Iranian construction sector's lack of knowledge and necessary skills (mean $=4.307$ ) is further exacerbated by an unavailability of professional consultants (mean score $=4.161$ ) to guide companies in implementing RM.

The lack of skills and the unavailability of skills are rooted in another issue that adversely affects the construction industry in developing countries, as explained at length by Kululanga (2012). The latter is a serious issue for Iran in light the international sanctions and the ever-increasing isolation of the country from developed economies and foreign investments, as noted by Perthes (2010). The lack of connections between academic university studies and the major practical problems facing the industry is a significant deficiency for developing countries Kululanga (2012).

\section{Lack of Agreement among the Project Parties and Stakeholders Regarding RM Implementation}

The barrier "Lack of agreement among the parties and stakeholders of projects regarding RM implementation", was ranked fourth overall by the respondents (mean = 3.909). This suggests that this concept is another hurdle in RM implementation within the Iranian construction industry. This finding is similar to the observations of other studies of developing countries, such as the Ghanaian construction industry study by Chileshe and Yirenkyi-Fianko (2012) and the study in Tanzania (Chileshe and Kikwasi, 2014).

The lack of agreement has been exacerbated by a lack of support for implementing RM from clients and project stakeholders. This mirrors the barriers identified by Chileshe and Kikwasi (2014) for the Tanzanian construction industry. Similarly, "Lack of joint RM" was identified by Tang et al. (2007) and Choudhry and labal (2013) as one of the major barriers to RM for construction projects in China and Pakistan. This is understandable in light of the common issues experienced in developing countries, i.e., a lack of "joint industry activities" and "effective coordination" among the main units of the construction industry as noted by 
Kululanga (2012). This could be a major barrier to the implementation of RM, as a lack of champions and managerial support in one party might hinder the implementation of RM and result in a diminished interest in RM among the other parties involved in the same project, as indicated by Silva, Wu and Ojiako (2013). According to Zhao et al. (2014), the commitment, support and leadership of a company's board and senior management are critical for implementing RM in projects.

\section{Project Constraints of Time and Cost That Inhibit the Use of Resources for RAMP}

According to Kutsch and Hall $(2009 ; 78)$, "the most dominant reason for the nonapplication of project RM appeared to be the problem of cost justification". However, construction practitioners in Iran regarded the time and cost required to implement RAMP as the 6th (mean = 3.430; $\mathrm{CV}=0.330$ ) and the 7th (mean = 3.273; $\mathrm{CV}=0.333$ ) items, respectively, in terms of the barriers hindering the implementation of RAMP in Iranian construction projects. This finding is also consistent with a number of selected studies of developing countries, including Chileshe and Kikwasi's (2013) study in Tanzania, which ranked these two time and cost RAMP barriers in the same 6th and 7th positions.

According to Kululanga (2012), a majority of the companies in developing countries are small and lack strategic vision and the capacity for growth. In essence, construction companies in developing countries usually suffer from a lack of resources to deliver projects (Perera et al., 2014). This is an issue in Iran, and irregular payments compound the problem as construction companies' struggle to cover their expenses and survive in the volatile market (Ghoddousi and Hosseini, 2012). Consequently, as shown in Table 5, cost concerns are a barrier to RAMP in a developing country such as Iran. However, as identified by Ghoddousi et al. (2015), pressure from the government (a major client of the construction industry) causes contractors to make the on-time completion of projects their first priority. Thus, as illustrated in Table 5, tight scheduling becomes one of the hurdles for RAMP.

As discussed above, the main barriers to RAMP were attributed to the lack of knowledge, skills and availability of skilled practitioners, which were encapsulated as the "Lack of formal RM systems". Two other categories, i.e., the "Lack of agreement and support among parties" and "Project constraints of time and cost" were of lower importance according to the respondents. However, as implied by Chileshe and Kikwasi (2014) and Choudhry and labal (2013), the lack of interest in RAMP could be attributed to the lack of knowledge and the lack of resources (time/cost). Moreover, as indicated by the seminal study by Slaughter (2000), due to this lack of knowledge and skills, organisations are not interested in allocating resources and time to implement new methods for delivering projects. These assumptions are presented in the form of the PLS-SEM model in Figure 1. 


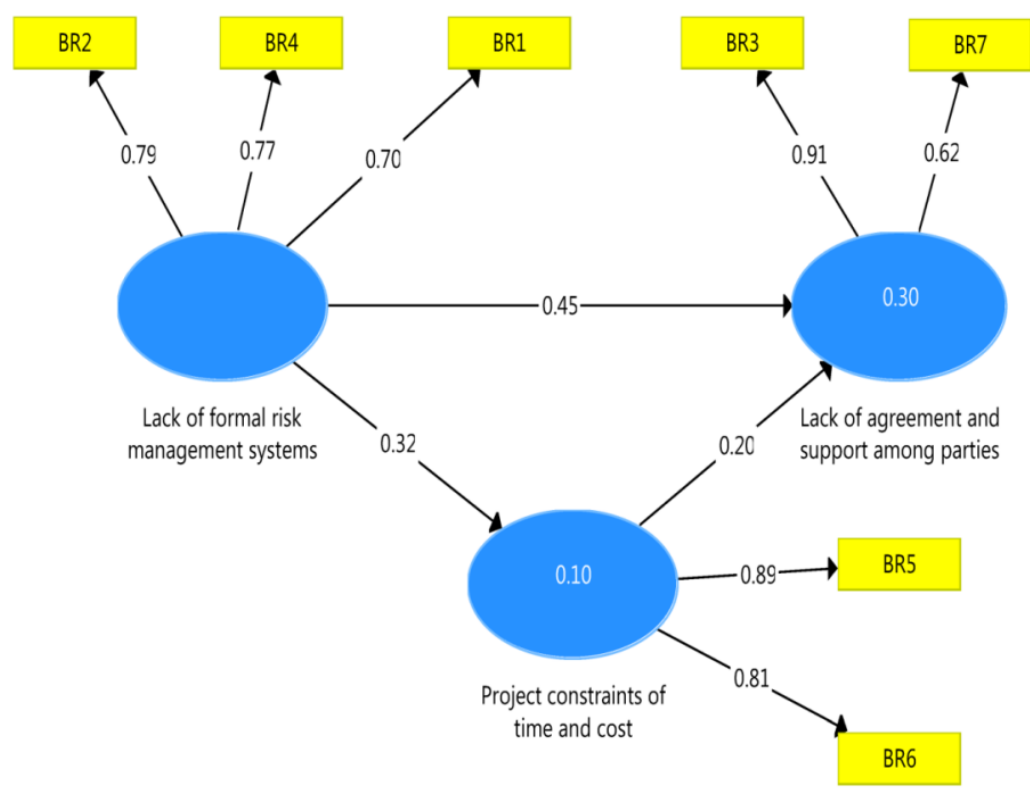

Figure 1. Associations between the Categories of Barriers (See Table 5 for Details of the Elements of the Model)

As illustrated in Figure 1, each category of barriers is considered a construct. These are concepts that are not directly measured and are usually shown using ovals in SEM models. The constructs reflect their indicators, which are variables that contain raw data and that are directly measured (rectangles in SEM models as described in Table 5). Single-headed arrows show the associations among the constructs and indicators. Using PLS-SEM models to analyse associations enables researchers to identify key target constructs and discover those that are acting as the drivers of others (Hair et al., 2014). The PLS algorithm was deployed to calculate the outer loadings between the elements of the model. The algorithm converged with eight iterations. A number of iterations below 300 implies that there is sufficient variability in the constructs in the model. The significance of the associations should be assessed by performing a bootstrapping test (Hair et al., 2014). The outcome of running the bootstrapping test is illustrated in Table 7.

Table 7. Significance of the Associations between the Constructs

\begin{tabular}{|c|c|c|c|c|c|}
\hline Associations & & & Outer Loadings & $T$ statistics & $P$ values \\
\hline $\begin{array}{l}\text { Lack of formal RM } \\
\text { systems }\end{array}$ & $\rightarrow$ & $\begin{array}{l}\text { Lack of agreement } \\
\text { and support } \\
\text { among parties }\end{array}$ & 0.45 & 5.290 & 0.000 \\
\hline $\begin{array}{l}\text { Lack of formal RM } \\
\text { systems }\end{array}$ & $\rightarrow$ & $\begin{array}{l}\text { Project constraints } \\
\text { of time and cost }\end{array}$ & 0.32 & 3.541 & 0.000 \\
\hline $\begin{array}{l}\text { Project constraints } \\
\text { of time and cost }\end{array}$ & $\rightarrow$ & $\begin{array}{l}\text { Lack of agreement } \\
\text { and support } \\
\text { among parties }\end{array}$ & 0.20 & 1.686 & 0.092 \\
\hline
\end{tabular}

100/PENERBIT UNIVERSITI SAINS MALAYSIA 
As illustrated in Figure 1 and Table 7, the outcome of the analysis shows a medium-sized (outer loading $=0.45$ ) and significant $(T$ statistics $=5.290>2.0$ ) association between "Lack of formal RM systems" and "Lack of agreement and support among parties". Therefore, the former could be the source and explanation for the latter as perceived by the respondents. Similarly, "Lack of formal RM systems" presented a medium (outer loading $=0.32$ ) and significant ( $T$ statistics $=3.541>2.0$ ) association to "Project constraints of time and cost". However, the association between "Project constraints of time and cost" and "Lack of agreement and support among parties" was weak (outer loading $=0.20$ ) and statistically insignificant ( $T$ statistics $=1.686<2.0$ ). This corroborated the ranking of the barriers associated with this category as the least important barriers to RAMP implementation, as shown in Table 5. As shown in Figure 1, for "Lack of agreement and support among parties", the R-square was equal to 0.3 ; thus, $30 \%$ of the variance in the category is explained by the elements associated with it, while $70 \%$ comes from elements not included in the model.

\section{RECOMMENDED SOLUTIONS AND GUIDELINES FOR RAMP IMPLEMENTATION}

The solutions below are suggested in the literature on RM in other developing countries. While these solutions are not verified by experts for the Iranian study, they are supported by a similar study of KM within Iranian project-based organisations (PBO) by Akhavan, Zahedi and Hosein (2014). The justification for the selection of this study is based on the similarities and linkages between KM and RM (Tah and Carr, 2001) and the context (country) under examination, namely Iran. The selection of this study is further corroborated in view of the outcome of the PLSSEM described above. That is, the category of barriers stemming from lack of skills and knowledge was the driver for the other categories and barriers identified in the present study.

1. Professional bodies lead RM training programmes: The Iranian study by Tabassi and Bakar (2009) identified low levels of education among the major problems facing Iranian construction workers. The proposed remedial solution from our RM study is to encourage the relevant professional associations of contractors, architects and professional bodies to introduce training programmes associated with the implementation of RM for their members. A similar "education and training" proposal has also been suggested as a solution for overcoming barriers in KM implementation among Iranian project-based organisations (Akhavan, Zahedi and Hosein, 2014). The above suggestion is supported by the RM study undertaken in the Pakistan context by Choudhry and labal (2013) and is further reinforced and supported by Tabassi and Bakar's (2009) study, which proposed that government legislate new rules and regulations for labour and provide training facilities.

2. Best practice from successful RM implementation case studies: Put "wins on the board" by documenting, publishing and communicating with contractors, consultants and clients about successful cases in which RM has been successfully introduced into projects and positive outcomes have been achieved (Chileshe and Kikwasi, 2013). 
3. RM knowledge as a prerequisite for licensing authorities: Provide training for construction practitioners through formal channels (Tabassi, Ramli and Bakar, 2012). The authorities responsible for issuing licences to contractor and consulting companies should require that the managers of companies possess a minimum level of RM knowledge as a prerequisite for receiving licenses. This would lift the basic skill level of the managers of the companies.

4. RM prerequisites for tendering procedures: Require that RM documents be submitted as part of the tendering procedures that relevant authorities use to award contracts as suggested by Goh and Abdul-Rahman (2013) and Perera et al. (2014).

5. Joint ventures with foreign contractors: Enhancing collaboration with foreign contractors is, according to Chileshe and Kikwasi (2014), a vehicle for construction practitioners in developing countries to acquire necessary and essential skills. Infrastructure projects in the oil and gas fields in Iran have often involved collaborations with international companies to deliver projects (Ebrahimnejad, Mousavi and Seyrafianpour, 2010). Such projects could be treated as available training opportunities for local contractors to acquire the knowledge and expertise necessary to implement RM in projects.

6. Integration of RM knowledge areas within training programmes for licensed engineers: Formally include knowledge requirements relating to RM in the curriculum of compulsory training programmes for licensed engineers. According to Arashpour, Shabanikia and Arashpour (2012), the Iranian construction industry is traditionally at the mercy of engineers. Thus, the strength of the construction industry in terms of implementing RM relies on the limited knowledge and abilities of engineers in the management sciences, including RM (Ghahramanzadeh, 2013).

7. Enhance organisational RM knowledge through training programmes: Increase the level of knowledge in organisations (Choudhry and lqbal, 2013). This could be pursued, particularly in government organisations, by including RM training subjects in the required training programmes for employees in organisations that act as clients in the Iranian construction industry.

8. Introduction of joint RM frameworks by independent experts: Joint RM frameworks should be developed and implemented for projects to guide clients and other stakeholders. As indicated by Ikediashi, Ogunlana and Alotaibi (2014), the commissioning of external experts by the government could facilitate this process and the development of the necessary materials.

9. Development of standards and codes: Standards and codes for joint RM should be developed, and their implementation should become compulsory in construction projects, as suggested by Choudhry and labal (2013).

10. Improved tendering procedures: Clients will not support RM implementation if they are not held accountable for the occurrence and consequences of risk (Kutsch and Hall, 2009). According to the current regulations in Iran, contractors suffer the majority of the consequences resulting from construction project risks (Ghahramanzadeh, 2013). Hence, all parties should be regarded as "risk owners" and held accountable according to the contractual requirements of construction projects. 
11. Resources necessary for implementing RAMP: As seen in Table 5, based on the overall sample, the two lowest ranked barriers relate to the "time" and "cost" aspects of completing a project. Interestingly, these barriers are also the lowest ranked when viewed by group (contractors, clients and consultants) (Table 5). These two barriers have been categorised under the heading "Resources necessary for implementing RAMP" because this last grouping is related to the project constraints of time and cost that inhibit the use of resources for RAMP.

12. Enhanced culture through the formalisation of RM procedures: This refers to enhancing the culture in the Iranian construction industry by formalising RM procedures in construction projects (Kutsch and Hall, 2009; Thaheem and De Marco, 2014). This could be achieved by relevant authorities introducing a mandatory framework for implementing RM in construction projects, as noted by Tadayon, Jaafar and Nasri (2012) and Perera et al. (2014).

13. Bridging the research gap between academia and industry: According to Cagliano, Grimaldi and Rafele (2015), knowledge of RM is becoming a matter of paramount importance to effectively address the complexity of projects. To encourage this knowledge creation, the gap between academia and the construction industry in Iran must be bridged. From the academic perspective, this objective should be pursued through research comparing the time and costs of implementing RAMP against the consequences of risk occurrences in construction projects, as suggested by Kutsch and Hall, (2009).

14. Streamlined approach to RM and lessons learned: Tadayon, Jaafar and Nasri's (2012) suggestion to reduce the cost of and time necessary for implementing RM by having a professional association prepare standardised documents and applicable templates and a database of risks and lessons learned might be an effective solution. Similarly, Ahmed, Kayis and Amornsawadwatana (2007) advocate building on "lessons learnt" by recommending that the measures used for projects' RAMP endeavours be based on existing knowledge of project management practices and lessons learned.

15. Enforcement of effective financial discipline: Improving the financial security of construction companies so that they focus less on immediate issues and instead consider overall projects and adopt a long-term perspective. The construction industry in a developing country, including in Iran, often suffers from the crippling effects of late and irregular payments to contractors and consultants, which result in a shortage of resources for implementing RAMP (Ghahramanzadeh, 2013). A better financial framework could enhance the financial security of contractors and consultants and thus lower this barrier.

\section{CORRELATION ANALYSIS}

To identify whether there are relationships and interactions among the identified RM barriers, Pearson's correlation coefficient is used as recommended by Cronk (2012). The results are summarised in Table 8. 


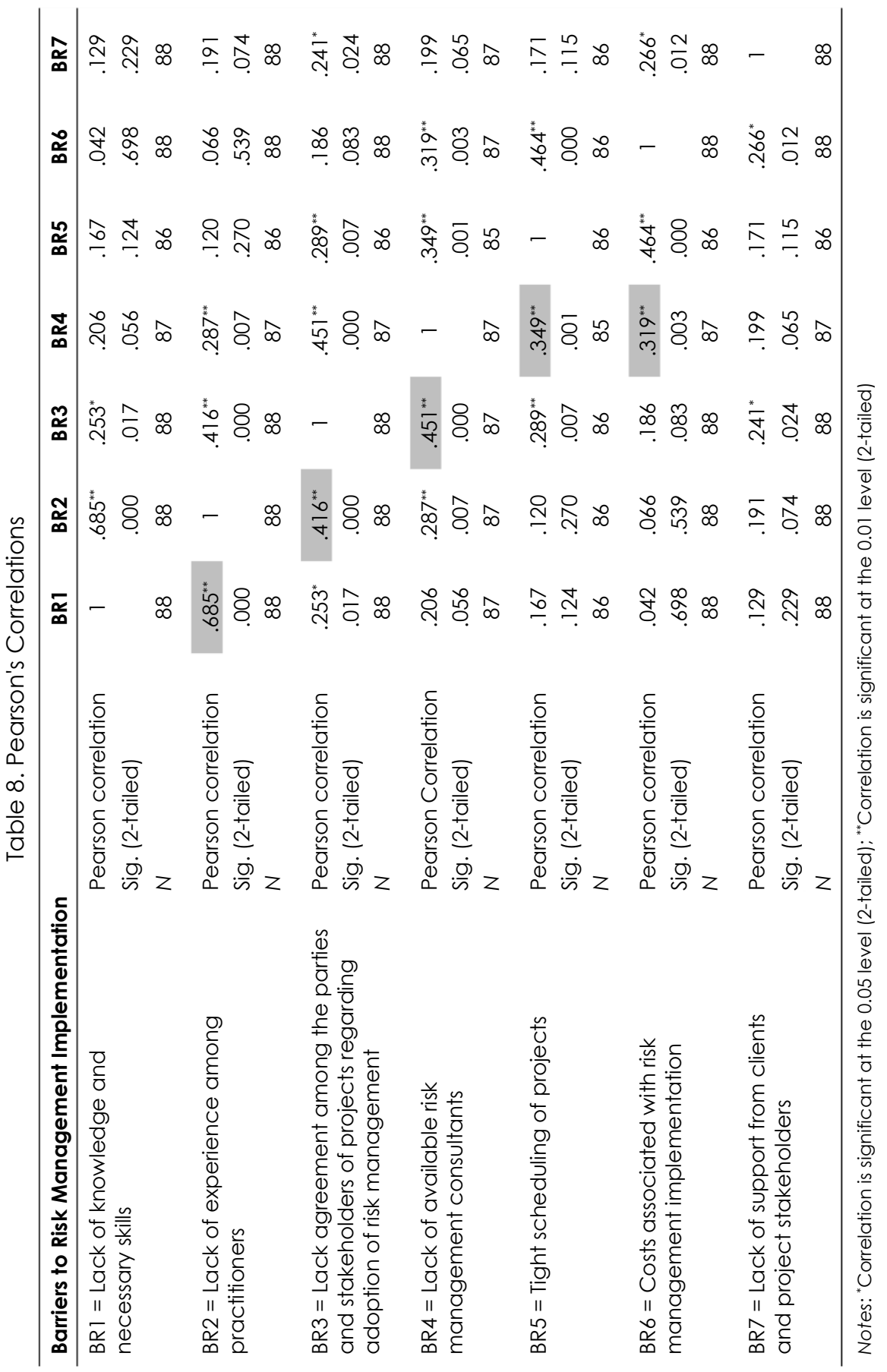

104/PENERBIT UNIVERSITI SAINS MALAYSIA 
For brevity, only the most significant correlations are commented upon here. An examination of Table 8 shows that eight (38\%) of the 21 correlations were significant at the $p<0.01$ level and that three (14.3\%) were significant at the $p<$ 0.05 levels. The analysis found a strong and positive correlation $(r(86)=0.685, p<$ 0.01 ) between "Lack of knowledge and necessary skills" and "Lack of experience among practitioners". This indicates that participants who identified the lack of knowledge and necessary skills as a barrier tended to also consider the lack of experience among practitioners as important.

\section{Spearman's Rank Coefficient}

Using the approach employed by Tang et al. (2007) to test whether there was consensus among the three groups (clients, contractors and consultants) on the rankings of the criticality (importance) of the barriers to RM, Spearman's rank correlation coefficient (Equation 1), $r_{s}$, was computed. The results are reported in Table 9.

Table 9. Spearman's Rank Coefficient

\begin{tabular}{lcc}
\hline \multirow{2}{*}{ Pairing } & \multicolumn{2}{c}{ Mean Scores } \\
\cline { 2 - 3 } & $\begin{array}{c}\text { Spearman's Rank } \\
\text { Correlation Coefficient }\end{array}$ & Significance Level \\
\hline Contractors - Clients & 0.821 & 0.05 \\
Clients - Consultants & 0.750 & 0.05 \\
Contractors - Consultants & 0.679 & 0.05 \\
\hline
\end{tabular}

An examination of Table 9 shows that the highest degree of agreement (correlation) occurred between the contractors and clients $182.1 \%$ with mean scores), which implies that there is a reasonably consistent view of the barriers to RM implementation. The lowest degree of agreement appears between contractors and consultants (approximately 67.9\%). The reason for this disparity among the three groups is open to conjecture, but it may be due to each group having a different perspective and thereby recognising different risk factors. This would require further study.

\section{CONCLUSION}

The purpose of this paper is to explore and identify the critical barriers to RM implementation within the Iranian construction sector. Based on the perception of major Iranian construction practitioners, the study found that there was limited knowledge and awareness of the implementation of RM in construction projects.

The research clearly indicated that a shift towards effective implementation of RAMP in developing countries will occur only if policy makers and researchers participate in a joint effort to enhance knowledge, supply the industry with necessary resources and provide a regulatory framework that encourages the spread of a risk culture. 
The study presents evidence that the viewpoints of all the key players in the Iranian construction industry are consistent with respect to their ranking of the barriers to the implementation of RAMP. It can be concluded that this agreement regarding the identification of barriers could be indicative of the available potential for overcoming these problems, as there may also be consensus among the key players in the construction industry regarding ways to address these barriers.

\section{Limitations and Future Areas for Research}

There is a conspicuous absence of investigations of the barriers to implementing RAMP in developing countries; thus, the present study is a significant contribution to the field. However, the findings should be considered in light of a number of limitations. These include the sample size of the study, which is relatively small. This opens the door for broader studies drawing upon larger sample sizes from different developing countries, which would provide more depth to the analysis of this topic. However, it could be suggested that not all developing countries demonstrate the same barriers to RAMP. It would be interesting for future studies to explore factors such as the proportion of itinerant workers utilised by the construction industry, the pervasive industry culture and other indicators of diversity.

Another limitation of the present study is that it provides a limited discussion of and suggestions for possible methods to reduce the barriers in developing countries. Industrial relations and regulatory frameworks might be different in different developing countries. Hence, new avenues for further research could be pursued by replicating this study in other developing countries using more comprehensive methods such as mixed methods. An analysis of remedial solutions drawing upon empirical studies from the construction industry for each developing country would also be a fertile area for further research.

\section{REFERENCES}

Abbott, M.L. (2011). Understanding Educational Statistics Using Microsoft Excelß and SPSS $\AA$. Hoboken, NJ: John Wiley and Sons.

Ahmed, A., Kayis, B. and Amornsawadwatana, S. (2007). A review of techniques for risk management in projects. Benchmarking: An International Journal, 14(1): 22-36. http://dx.doi.org/10.1108/14635770710730919.

Akhavan, P., Zahedi, M.R. and Hosein, S.H. (2014). A conceptual framework to address barriers to knowledge management in project-based organizations. Education, Business and Society: Contemporary Middle Eastern Issues, 7(2/3): 98-119. http://dx.doi.org/10.1108/EBS-10-2013-0040.

Alavifar, A.M. and Motamedi, S. (2014). Identification, evaluation and classification of time delay risks of construction projects in Iran. Paper presented at the International Conference on Industrial Engineering and Operations Management. Bali, Indonesia, 7-9 January. 
Amaratunga, D., Baldry, D., Sarshar, M. and Newton, R. (2002). Quantitative and qualitative research in the built environment: Application of "mixed" research approach. Work Study, 51(1): 17-31. http://dx.doi.org/ $10.1108 / 00438020210415488$.

Arashpour, M., Shabanikia, M. and Arashpour, M. (2012). Valuing the contribution of knowledge-oriented workers to projects: A merit based approach in the construction industry. Australasian Journal of Construction Economics and Building, 12(4): 1-12. http://dx.doi.org/10.5130/ajceb.v12i4.2724.

Banaitienè, N., Banaitis, A. and Norkus, A. (2011). Risk management in projects: Peculiarities of Lithuanian construction companies. International Journal of Strategic Property Management, 15(1): 60-73. http://dx.doi.org/10.3846/ $1648715 X .2011 .568675$.

Bowers, J. and Khorakian, A. (2014). Integrating risk management in the innovation project. European Journal of Innovation Management, 17(1): 25-40. http://dx.doi.org/10.1108/EJIM-01-2013-0010.

Cagliano, A.C., Grimaldi, S. and Rafele, C. (2015). Choosing project risk management techniques: A theoretical framework. Journal of Risk Research, 18(2): 232-248. http://dx.doi.org/10.1080/13669877.2014.896398.

Carless, S.A. and De Paola, C. (2000). The measurement of cohesion in work teams. Small Group Research, 31(1): 71-88. http://dx.doi.org/10.1177/10464964 0003100104.

Carter, A. and Chinyio, E. (2012). Effectiveness of risk management: Barriers and solutions. International Journal of Project Organisation and Management, 4(4): 368-378. http://dx.doi.org/10.1504/IJPOM.2012.050330.

Cheung, E., Chan, A.P.C., Lam, P.T.I., Chan, D.W.M. and Ke, Y. (2012). A comparative study of critical success factors for public private partnerships (PPP) between Mainland China and the Hong Kong Special Administrative Region. Facilities, 30(13/14): 647-666. http://dx.doi.org/10.1108/0263277 1211273132.

Chileshe, N. and Kikwasi, G.J. (2014). Critical success factors for implementation of risk assessment and management practices within the Tanzanian construction industry. Engineering, Construction and Architectural Management, 21 (3): 291-319. http://dx.doi.org/10.1108/ECAM-01-2013-0001.

Chileshe, N. and Kikwasi, G.J. (2013). Perception of barriers to implementing risk assessment and management practices by construction professionals in Tanzania. In S.D. Smith and D.D. Ahiaga-Dagbui (eds.). 29th Annual ARCOM Conference. Reading, UK, 2-4 September. Reading, UK: Association of Researchers in Construction Management, 1137-1146.

Chileshe, N. and Yirenkyi-Fianko, A.B. (2012). An evaluation of risk factors impacting construction projects in Ghana. Journal of Engineering, Design and Technology, 10(3): 306-329. http://dx.doi.org/10.1108/17260531211274693.

Choudhry, R. and Iqbal, K. (2013). Identification of risk management system in construction industry in Pakistan. Journal of Management in Engineering 29(1): 42-49. http://dx.doi.org/10.1061/(ASCE)ME.1943-5479.0000122.

Cronk, B.C. (2012). How to Use SPSS: A Step-By-Step Guide to Analysis and Interpretation. 7th Ed. Glendale, CA: Pyrczak Pub. 
Deng, X., Low, S., Li, Q. and Zhao, X. (2014). Developing competitive advantages in political risk management for international construction enterprises. Journal of Construction Engineering and Management, 140(9): 04014040-110.

Ebrahimnejad, S., Mousavi, S.M. and Seyrafianpour, H. (2010). Risk identification and assessment for build-operate-transfer projects: A fuzzy multi attribute decision making model. Expert Systems with Applications, 37(1): 575-586. http://dx.doi.org/10.1016/j.eswa.2009.05.037.

Fallahi, A. (2008). Bam earthquake reconstruction assessment: An interdisciplinary analytical study on the risk preparedness of Bam and its cultural landscape: A World Heritage property in danger. Structural Survey, 26(5): 387-399. http://dx.doi.org/10.1108/02630800810922739.

Fereidouni, H.G. (2011). Factors contributing to the fluctuations in residential construction in Iran. Australasian Journal of Construction Economics and Building, 11 (4): 77-86. http://dx.doi.org/10.5130/ajceb.v1 1i4.2295.

Forza, C. (2002). Survey research in operations management: A process-based perspective. International Journal of Operations and Production Management, 22(2): 152-194. http://dx.doi.org/10.1108/01443570210414310.

Ghahramanzadeh, M. (2013). Managing risk of construction projects a case study of Iran. PhD diss. University of East London.

Ghoddousi, P. and Hosseini, M.R. (2012). A survey of the factors affecting the productivity of construction projects in Iran. Technological and Economic Development of Economy, 18(1): 99-116. http://dx.doi.org/10.3846/ 20294913.2012.661203.

Ghoddousi, P., Bahrami, N., Chileshe, N. and Hosseini, M.R. (2014). Mapping sitebased construction workers' motivation: Expectancy theory approach. Australasian Journal of Construction Economics and Building, 14(1): 60-77. http://dx.doi.org/10.5130/ajceb.v14i1.3712.

Ghoddousi, P., Poorafshar, O., Chileshe, N. and Hosseini, M.R. (2015). Labour productivity in Iranian construction projects. International Journal of Productivity and Performance Management, 64(6): 811-830. http://dx.doi.org/10.1108/IJPPM-10-2013-0169.

Goh, C.S. and Abdul Rahman, H. (2013). The identification and management of major risks in the Malaysian construction industry. Journal of Construction in Developing Countries, 18(1): 19-32.

Hair Jr, J.F., Hult, G.T.M., Ringle, C. and Sarstedt, M. (2014). A Primer on Partial Least Squares Structural Equation Modeling (PLS-SEM). Thousand Oaks, CA: Sage Publications.

Hair, J.F., Sarstedt, M., Pieper, T.M. and Ringle, C.M. (2012). The use of partial least squares structural equation modeling in strategic management research: A review of past practices and recommendations for future applications. Long Range Planning, 45(5-6): 320-340. http://dx.doi.org/10.1016/j.Irp.2012.09.008.

Harner, M.M. (2010). Barriers to effective risk management. Seton Hall Law Review, 40(4): 1323-1366.

Hwang, B.-G., Zhao, X. and Toh, L.P. (2014). Risk management in small construction projects in Singapore: Status, barriers and impact. International Journal of Project Management, 32(1): 116-124. http://dx.doi.org/10.1016/j.ijproman. 2013.01.007. 
Ifpinfo.com. (2014). Thriving construction industry in Iran. Ifpinfo.com: Middle East Business News and Events. Beirut: IFP Group. Available at: http://www.ifpinfo.com/Iran-NewsArticle-5250\#.Vb1U3_mlV1B [Accessed on 2 August 2015].

Ikediashi, D.I., Ogunlana, S.O. and Alotaibi, A. (2014). Analysis of project failure factors for infrastructure projects in Saudi Arabia: A multivariate approach. Journal of Construction in Developing Countries, 19(1): 35-52.

International Monetary Fund (IMF). (2014). 2014 Article IV Consultation: Staff Report; Press Release; and Statement by the Executive Director for the Islamic Republic of Iran. IMF Country Report No. 14/93. Washington DC: IMF.

Jafari, M., Akhavan, P., Nour, J.R. and Fesharaki, M.N. (2007). Knowledge management in Iran aerospace industries: A study on critical factors. Aircraft Engineering and Aerospace Technology, 79(4): 375-389. http://dx.doi.org/10.1 108/00022660710758240.

Jafari, M., Rezaeenour, J., Mazdeh, M.M. and Hooshmandi, A. (2011). Development and evaluation of knowledge risk management model for project-based organizations: A multi-stage study. Management Decisions, 49(3): 309-329. http://dx.doi.org/10.1108/00251741111120725.

Jahangiri, K., Izadkhah, Y.O. and Jamaledin Tabibi, S. (2011). A comparative study on community-based disaster management in selected countries and designing a model for Iran. Disaster Prevention and Management: An International Journal, 20(1): 82-94. http://dx.doi.org/10.1108/0965356 1111111108 .

KarimiAzari, A., Mousavi, N., Mousavi, S.F. and Hosseini, S. (2011). Risk assessment model selection in construction industry. Expert Systems with Applications, 38(8): 9105-9111. http://dx.doi.org/10.1016/j.eswa.2010.12.110.

Kazaz, A. and Ulubeyli, S. (2007). Drivers of productivity among construction workers: A study in a developing country. Building and Environment, 42(5): 2132-2140. http://dx.doi.org/10.1016/j.buildenv.2006.04.020.

Khan, O. and Burnes, B. (2007). Risk and supply chain management: Creating a research agenda. The International Journal of Logistics Management, 18(2): 197-216. http://dx.doi.org/10.1108/09574090710816931.

Kikwasi, G.J. (2011). An assessment of risk management practices by consultants in Tanzania. In T.C. Haupt (ed.). Proceedings of the 6th Built Environment. Johannesburg, South Africa, 31 July-2 August. Johannesburg, South Africa: Association of Schools of Construction, 302-314.

Kim, S. and Bajaj, D. (2000). Risk management in construction: An approach for contractors in South Korea. Cost Engineering, 42(1): 38-44.

Kululanga, G. (2012). Capacity building of construction industries in Sub-Saharan developing countries. Engineering, Construction and Architectural Management, 19(1): 86-100. http://dx.doi.org/10.1108/09699981211192580.

Kutsch, E. and Hall, M. (2009). The rational choice of not applying project risk management in information technology projects. Project Management Journal, 40(3): 72-81. http://dx.doi.org/10.1002/pmj.20112.

Liu, J., Li, B., Lin, B. and Nguyen, V. (2007). Key issues and challenges of risk management and insurance in China's construction industry: An empirical study. Industrial Management and Data Systems, 107(3): 382-396. http://dx.doi.org/10.1 108/02635570710734280. 
Liu, J.Y., Low, S.P. and He, X. (2011). Current practices and challenges of implementing enterprise risk management (ERM) in Chinese construction enterprises. International Journal of Construction Management, 11 (4): 49-63. http://dx.doi.org/10.1080/15623599.2011.10773178.

Lyons, T. and Skitmore, M. (2004). Project risk management in the Queensland engineering construction industry: A survey. International Journal of Project Management, 22(1): 51-61. http://dx.doi.org/10.1016/S0263-7863 (03)00005-X.

Moavenzadeh, F. (1978). Construction industry in developing countries. World Development, 6(1): 97-1 16. http://dx.doi.org/10.1016/0305-750X(78)90027-X.

Mojtahedi, S.M.H., Mousavi, S.M. and Makui, A. (2010). Project risk identification and assessment simultaneously using multi-attribute group decision making technique. Safety Science, 48(4): 499-507. http://dx.doi.org/10.1016/ j.ssci.2009.12.016.

Nateghi-A., F. (2000). Existing and proposed earthquake disaster management organization for Iran. Disaster Prevention and Management: An International Journal, 9 (3): 200-205. http://dx.doi.org/10.1 108/09653560010335130.

Ofori, G. and Toor, S. (2012). Leadership and construction industry development in developing countries. Journal of Construction in Developing Countries, 17(Suppl. 1): 1-21.

Paape, L. and Speklè, R.F. (2012). The adoption and design of enterprise risk management practices: An empirical study. European Accounting Review. 21 (3): 533-564. http://dx.doi.org/10.1080/09638180.2012.661937.

Parsizadeh, F. and Ghafory-Ashtiany, M. (2010). Iran public education and awareness program and its achievements. Disaster Prevention and Management: An International Journal, 19(1): 32-47. http://dx.doi.org/10.1108/09653561011022126.

Perera, B.A.K.S., Rameezdeen, R., Chileshe, N. and Hosseini, M.R. (2014). Enhancing the effectiveness of risk management practices in Sri Lankan road construction projects: A Delphi approach. International Journal of Construction Management, 14(1): 1-19. http://dx.doi.org/10.1080/15623599. 2013.875271.

Perthes, V. (2010). Ambition and fear: Iran's foreign policy and nuclear programme. Survival, 52(3): 95-114. http://dx.doi.org/10.1080/00396338. 2010.494879.

Pournader, M., Tabassi, A.A. and Baloh, P. (2015). A three-step design science approach to develop a novel human resource-planning framework in projects: The cases of construction projects in USA, Europe, and Iran. International Journal of Project Management, 33(2): 419-434. http://dx.doi.org/10.1016/j.jpproman.2014.06.009.

Rao Tummala, V.M., Leung, H.M., Mok, C.K., Burchett, J.F. and Leung, Y.H. (1997). Practices, barriers and benefits of using risk management approaches in selected Hong Kong industries. International Journal of Project Management, 15(5): 297-312. http://dx.doi.org/10.1016/S0263-7863(96) 00082-8.

Ringle, C.M., Sarstedt, M. and Straub, D. (2012), A critical look at the use of PLS-SEM in MIS Quarterly. MIS Quarterly (MISQ), 36(1): iii-xiv.

Roudsari, B.S. and Ghodsi, M. (2005). Occupational injuries in Tehran. Injury, 36(1): 33-39. http://dx.doi.org/10.1016/j.injury.2003.10.034.

110/PENERBIT UNIVERSITI SAINS MALAYSIA 
Sharifirad, M.S. (2011). The dimensions of learning organization questionnaire (DLOQ). International Journal of Manpower, 32(5/6): 661-676. http://dx.doi.org/10.1108/01437721111158251.

Silva, E.S., Wu, Y. and Ojiako, U. (2013). Developing risk management as a competitive capability. Strategic Change, 22(5-6): 281-294. http://dx.doi.org/10.1002/jsc.1940.

Slaughter, E.S. (2000). Implementation of construction innovations. Building Research and Information, 28(1): 2-17. http://dx.doi.org/10.1080/0961321 00369055.

Tabassi, A.A. and Bakar, A.H.A. (2009). Training, motivation, and performance: The case of human resource management in construction projects in Mashhad, Iran. International Journal of Project Management, 27(5): 471-480. http://dx.doi.org/10.1016/j.jpproman.2008.08.002.

Tabassi, A.A., Ramli, M. and Bakar, A.H.A. (2012). Effects of training and motivation practices on teamwork improvement and task efficiency: The case of construction firms. International Journal of Project Management, 30(2): 213224. http://dx.doi.org/10.1016/j.ijproman.2011.05.009.

Tadayon, M., Jaafar, M. and Nasri, E. (2012). An assessment of risk identification in large construction projects in Iran. Journal of Construction in Developing Countries, 17(1): 57-69.

Tah, J.H.M. and Carr, V. (2001). Knowledge-based approach to construction project risk management. Journal of Computing in Civil Engineering, 15(3): 170-177. http://dx.doi.org/10.1061/(ASCE)0887-3801 (2001)15:3(170).

Tang, W., Qiang, M., Duffield, C.F., Young, D.M. and Lu, Y. (2007). Risk management in the Chinese construction industry. Journal of Construction Engineering and Management, 133(12): 944-956. http://dx.doi.org/10.1061/ (ASCE)0733-9364(2007)133:12(944).

Tarokh, M.J., Sharifi, E. and Nazemi, E. (2008). Survey of BPR experiences in Iran: Reasons for success and failure. Journal of Business and Industrial Marketing, 23(5): 350-362. http://dx.doi.org/10.1 108/08858620810881629.

Tavakkoli-Moghaddam, R., Mousavi, S. and Hashemi, H. (2011). A Fuzzy Comprehensive Approach for Risk Identification and Prioritization Simultaneously in EPC Projects. Rijeka, Croatia: InTech Publisher, 123-146. http://dx.doi.org/10.5772/16247.

Thaheem, M.J. and De Marco, A. (2014). Sustainable repair and maintenance of buildings in the developing countries: A risk management perspective and proposal of customized framework. Journal of Civil Engineering and Architecture Research, 1(1):14-23.

Wang, J. and Yuan, H. (2011). Factors affecting contractors' risk attitudes in construction projects: Case study from China. International Journal of Project Management, 29(2): 209-219. http://dx.doi.org/10.1016/j.ijproman. 2010.02.006.

Wang, S.Q., Dulaimi, M.F. and Aguria, M.Y. (2004). Risk management framework for construction projects in developing countries. Construction Management and Economics, 22(3): 237-252. http://dx.doi.org/10.1080/0144619032000 124689. 
Wang, X., Fang, D. and Pham, L. (2009). Risk assessment of Australian construction and engineering firms in China. International Journal of Construction Management, 9(2): 119-131. http://dx.doi.org/10.1080/15623599.2009. 10773134.

Zadeh, M.G. (2010). Risk management implementation in the iranian construction industry from contractors' perspective. MSc diss. Universiti Teknologi Malaysia.

Zhao, X., Hwang, B.G. and Low, S.P. (2013). Developing fuzzy enterprise risk management maturity model for construction firms. Journal of Construction Engineering and Management, 139(9): 1179-1 189. http://dx.doi.org/10.1061/ (ASCE)CO.1943-7862.0000712.

Zhao, X., Hwang, B.-G., Low, S.P. and Wu, P. (2014). Reducing hindrances to enterprise risk management implementation in construction firms. Journal of Construction Engineering and Management, 141(3): 04014083. http://dx.doi.org/10.1061/(ASCE)CO.1943-7862.0000945.

Zou, P.X., Zhang, G. and Wang, J.-Y. (2006). Identifying key risks in construction projects: Life cycle and stakeholder perspectives. Proceedings: The 12th Annual Conference of the Pacific Rim Real Estate Society. The University of Auckland Business School, Auckland, New Zealand, 22-25 January. Auckland, New Zealand: Pacific Rim Real Estate Society (PRRES). 